TABLE 7

APSA National Salary Scale 1994-95

\begin{tabular}{|c|c|c|c|c|c|c|}
\hline \multirow[b]{2}{*}{ APSA Position } & \multirow{2}{*}{$\begin{array}{c}\text { Equivalent } \\
\text { Government } \\
\text { Grade }\end{array}$} & \multirow{2}{*}{$\begin{array}{c}1994 \\
\text { Federal } \\
\text { Salary Scale }\end{array}$} & \multirow{2}{*}{$\begin{array}{c}1994-95 \\
\text { APSA } \\
\text { Grade }\end{array}$} & \multirow{2}{*}{$\begin{array}{c}\text { 1994-95 } \\
\text { APSA } \\
\text { Salary Scale } \\
\end{array}$} & \multicolumn{2}{|c|}{$\begin{array}{l}\text { Number of } \\
\text { Employees }\end{array}$} \\
\hline & & & & & FT & PT \\
\hline \multicolumn{7}{|l|}{ Political Scientists: } \\
\hline Executive Director & SES & $92,900-115,700$ & 8 & $84,000-99,500$ & 1 & \\
\hline Deputy Director & 15 & $69,427-90,252$ & 7 & $63,000-89,000$ & 1 & \\
\hline Program Directors & $13-14$ & $49,947-76,733$ & 6 & $47,000-83,000$ & 2 & 1 \\
\hline \multicolumn{7}{|l|}{ Non-Political Scientists: } \\
\hline Program Managers & $11-12$ & $35,045-54,601$ & 5 & $33,500-43,000$ & 4 & \\
\hline $\begin{array}{l}\text { Senior Administrative } \\
\text { Asst. }\end{array}$ & $9-10$ & $28,964-41,466$ & 4 & $27,500-39,500$ & 3 & \\
\hline $\begin{array}{l}\text { Administrative Asstistant; } \\
\text { Building Manager }\end{array}$ & $7-8$ & $23,678-34,094$ & 3 & $21,000-34,000$ & 5 & \\
\hline Secretary, Receptionist & $4-6$ & $17,086-27,696$ & 2 & $18,900-28,500$ & 4 & \\
\hline Clerk & $1-3$ & $12,406-19,789$ & 1 & $16,800-19,900$ & 1 & \\
\hline
\end{tabular}

Daniels, Naomi Lynn, and Jack Peltason) for the generous gift of their time and wise counsel and, in particular, to Jim Caporaso for his stewardship and excellent advice to the incoming treasurer.

\section{Report of the Managing Editor of the American Political Science Review, 1993-94}

\section{G. Bingham Powell, Jr., University of Rochester}

These reports have usually focused on quantity, equity, and timeliness in the review and publication process. They provide useful and (relatively) comparable information about these dimensions of our activities. Yet, they tell only part of the story. They say little about our efforts to achieve quality. I begin this report by discussing in more depth our efforts to attain quality in two areas: We seek to provide analyses that help authors improve manuscripts that are rejected for publication at the $R e$ view. We also attempt to publish in the Review itself manuscripts that meet the highest standards of the discipline today.

\section{Advice on Rejected Manuscripts}

The Seminar by Mail: The Referees. When I began my term as $A P S R$ Managing Editor, I had hoped at least to continue, or even improve, the APSR tradition of giving useful advice to authors of manuscripts that we do not publish. This is an important service to the discipline, especially as we reject $90 \%$ of the manuscripts and take 3-4 months to do it. We hope this is not just wasted time. I thought there would be two elements in achieving this. One element would be the solicitation of good panels of referees, including on every panel at least one referee with necessary technical skills and at least one slightly more distant from the immediate research. Ideally, then, the rejected author learns from these referees how his or her reported scholarship is being seen by the best scholars directly in his or her field, also learns about reception by a slightly broader audience, and receives advice on any technical difficulties.

These principles are much easier to state than to implement. It is particularly hard to get a balanced panel. Moreover, at any given time many referees will be in use, which means that the ideal reader may not be available, especially at certain times of the year. We try not to send a manuscript to a referee who has another of our manuscripts or who has returned an evaluation in the last six weeks. Also, a few-but fortunately very few-highly regarded scholars simply refuse to participate in the refereeing process. (I find it hard to manuscript and have taken to tellbe sympathetic when they submit a ing them so.) By consulting the Editorial Board on virtually every manuscript, I think we have generally done a good job with referee selection, especially in getting technically qualified people on the panels of referees. We have drawn into the review process many young scholars, largely recommended by experts on the Editorial Board, whose work is just becoming known. Their help is especially important for manuscripts using new techniques of analysis with which many of their better known senior colleagues may not be familiar.

I think that the make-up of most-but admittedly not all-of our panels would withstand expert scrutiny as at least a reasonable approximation of what is desirable. Still, the quality of the reports themselves depends on the efforts of the reviewers. Some referees deliver superbly thoughtful, even creative, reviews that would be of great help to any scholar's research program. The majority provide solid advice and analysis that should help authors understand the reception of a given paper, its perceived strengths and limitations. Some, unfortunately, provide much more perfunctory comments, which are frustrating to both author and editor. In a few cases these reviews are accompanied by (or consist of) brutal and gratuitous negative comments that serve no useful purpose. I sometimes delete the most painful of these; in other cases I cannot do so without having the author misread the nature of the recommendation. In the latter cases I attempt at least to apologize for the referee's ill-temper. Naturally, I tend over time to try to eliminate those referees that provide unhelpful reviews.

Sometimes, by the way, referees reprimand me for sending them a manuscript that is not "worthy" of their time and effort. In a few cases they are right, and I should have known enough to reject the manuscript without review. Mostly, they are not right; it is particularly amusing to receive such a letter in conjunction with at least one other report in which the referee especially liked the paper and considered it superb. (This happened twice in 1993-94.) In any case, I 
try to remind my referees that if they do not review a weak paper, it may have to go to a less competent reader-who may like it.

In general, the referees do a remarkable job and one which serves the profession well. I think that the "seminar by mail" does largely constructive work, even while $90 \%$ of the manuscripts are being rejected.

\section{The Seminar by Mail: Editor's} Comments. I initially hoped also to contribute to improving the quality and research programs of scholarship that must be rejected by offering helpful analysis from the Managing Editor. I do try carefully to interpret the reviews for the author, especially when the referee gives me additional comments. However, I have found it impossible for me to read every manuscript submitted to $A P S R$. The most I can do is briefly to skim them to see that the referees are, indeed, talking about the right manuscript. In the cases where manuscripts receive two clearly negative reviews, (about a third of all submitted manuscripts, as noted below), I rarely add further personal input. I wish I could do more, but this is a choice that has emerged in allocating my time.

In cases of manuscripts receiving some encouraging reviews, I try to read, or at least glance at, the manuscripts as well as the reviews, and usually give the author my own suggestions and interpretation. The extent to which I can do this usefully depends on the field. In some fields I can do quite a bit, if only to place the referee comments in the context of other reviews I see on similar work. In other fields (particularly in formal theory and normative theory), I can only comment on the accessibility of the work to the nonspecialist. In all cases when I offer advice, I try to preface it with acknowledgment of my limitations in an area.

\section{Manuscripts That Seem Likely Candidates for Publication}

I read as carefully as I can all articles that emerge from the ref- eree process as likely candidates for publication in the Review.

When I encourage an author to revise and resubmit a manuscript, I try to give clear signals about what I think are the strengths and weaknesses of the manuscript and to which referees I would return on a second round. (We usually return to the two less favorable referees and one new referee.) I try not to give such encouragement unless I think the odds of acceptance are at least $50 / 50$. In cases where the odds seem less than that, but I can see ways to revise that might give an interesting manuscript a real chance, I offer a "soft" rejection that leaves open the possibility of reviewing a substantially revised version. I suggest possible (or necessary) lines of approach if I can. On the other side, if the initial referee support is unanimous and strong (a pretty rare event), I still try to advise the author on any respects in which I think the manuscript could be strengthened, even if I do not make changes a requirement for acceptance.

I find that I spend a great deal of time working with "soft reject," "revise/resubmit," or "nearly accept" manuscripts. Sometimes I have been able to put authors in touch with leading technical experts to help them rework their technical analyses; this has resulted in marked improvement in substantively interesting, but technically flawed, manuscripts. Sometimes, I have been able to make a contribution myself, which is deeply satisfying, although of course the effects are almost always marginal. I always press authors to take seriously the advice of thoughtful referees, whether or not they seem sympathetic.

It is hard to know how much of my work results in improvement of the articles. It clearly results in changes in many articles, although, again, much more in some fields than in others. (I have learned through painful experience that my advice in normative theory is as likely to be harmful as helpful to manuscripts that will go back to the referees, and I try to warn the authors to that effect.) I think most papers are better after serious revi- sion, and most of the manuscripts that receive encouragement will be published elsewhere, if not ultimately in the Review.

Authors have been generous with comments of appreciation for my efforts at advising them, although by the nature of the situation I cannot take their comments too seriously. (If they appear in the notes, these thanks are always deleted before publication.) At times I have put authors through very hard work by requiring revisions, and even re-revisions before publication. They have shown remarkable tolerance of my intervention, understanding, (I hope), that my efforts, however misguided, are aimed at the common objective of improving the final product, not personal gratification. (I certainly hope this is true.)

Ultimately, as revealed by this account, I have come to choose as my personal priority the publication of the best papers in the Review, rather than more complete participation in the "seminar by mail." (However, I have spent a lot of time with some manuscripts that seemed likely candidates, but were ultimately rejected.) "Best" means not only survival in a review process of the best scholars, but improvement of the original manuscript to achieve the highest quality it can achieve.

Beyond my efforts to encourage substantive quality, I also work to try to improve the accessibility of the manuscripts to our readers. Sometimes this is a matter of language and organization; often it has to do with presentation of figures and tables. Our copy editor, Michael Lane, and Associate Editor Linda Lindenfelser also work hard, (often, but not exclusively, at a more fine-grained level), to improve the readability of manuscripts. Most authors accept these efforts with grace and even appreciation.

There is no immediate, reliable, valid test of success in publishing quality. We must let the case rest in the hands of the current readers and, beyond, in the development of the discipline over the next decade. It is satisfying to participate (even in a limited way) in some of the 
most exciting scholarship currently underway. Thus, we are intrinsically rewarded for our efforts. We hope that the Review also bears positive traces of them.

\section{The Flow of New Manuscripts}

Table 1 shows the absolute number of manuscripts received in 1993-94, as well as the distribution across subfields of political science. The flow of new manuscripts continued at very much the same rate as in my two previous years as Managing Editor, about 480 manuscripts a year. The average for the last five years of Patterson's editorship is shown in data column 1.

The comparison suggests about a $10 \%$ increase in submitted manuscripts.

All the totals in Table 1, including those of the previous periods, include revisions of previously submitted manuscripts. About $90 \%$ of the manuscripts are being seen for the first time, while the remainder are revisions of manuscripts previously submitted. The table does not include seven manuscripts that could not be classified as political science and were rejected for that reason.

The distribution across subfields also remains fairly consistent. In comparison to the earlier period we are seeing slightly fewer manuscripts in American politics and formal theory, slightly more in the other fields, especially comparative politics. But most of the differences are slight. As we are receiving more total manuscripts, the decline in American politics amounts to about ten fewer manuscripts a year. The increase in comparative politics had already begun towards the end of Patterson's term; the increase in normative political theory does reverse a slight pattern of decline. Depending on the year we consider, the increases in comparative and normative theory amount to 20 or more manuscripts a year.

I should add that while in most cases the classification of manuscripts is fairly straightforward, a number of manuscripts cut across two (or even more) fields. It seems to me that this is a growing tendency across all the subfields. This tendency is, doubtless, healthy for political science, but troubling for this kind of classification. I have tried to classify the manuscripts in terms of the predominant thrust of the manuscript and the main community of readers that it is trying to address.

\section{The Acceptance of Manuscripts}

Table 2 shows the distribution across fields in manuscripts published or scheduled for publication in 1994. The increase in APSR space following the 1992 format change (to the $8 \frac{1}{2}$ by 11 inch paper size) made possible an increase in the number of articles, while also increasing the size of the Book Review. Although I am fighting a per-

\section{TABLE 1}

Distribution of Manuscripts Submitted to the APSR by Subfield in 1985-1991 and from 1991-92 to 1993-1994

\begin{tabular}{lcccc}
\hline \multicolumn{1}{c}{ Subfield } & $\begin{array}{c}\text { Average } \\
\text { 1985-1991* }\end{array}$ & 1991-1992 & $1992-1993$ & 1993-1994 \\
\hline $\begin{array}{l}\text { American Politics and } \\
\quad \text { Public Policy }\end{array}$ & $41 \%$ & $34 \%$ & $37 \%$ & $34 \%$ \\
Comparative Politics & 17 & 20 & 20 & 24 \\
Normative Political Theory & 19 & 21 & 24 & 21 \\
International Relations & 10 & 14 & 9 & 11 \\
Formal Theory & 13 & 10 & 10 & 10 \\
Total & $100 \%$ & $99 \%$ & $100 \%$ & $100 \%$ \\
Number of Manuscripts & 426 & 479 & 487 & 480 \\
\hline${ }^{*}$ Calculated from Patterson, Bruce, and Crone 1991, p. 766, Table 1. Average number in- \\
cludes only last five years. Manuscripts submitted include both new manuscripts and revi- \\
sions of previously submitted manuscripts. In the three most recent years there were 50, \\
47, and 46 revisions respectively.
\end{tabular}

petual, and seemingly hopeless, battle to limit the size of manuscripts, thus far the increase in space is being consumed by more articles, not longer ones.

As usual, the distribution of published articles across fields roughly shadows the distribution of submitted manuscripts. It is worth noting that the majority of published manuscripts go through a "revise and resubmit" stage, so in some cases a substantial lag can appear. But it is roughly fair to say that publication of manuscripts in a given field responds above all else to the number of manuscripts submitted in that field.

Table 3 shows equity in a different way, by presenting acceptance rates by subfield. Calculation of these rates is somewhat problematic, as explained in previous Annual Reports. The numbers shown here for my editorship are based on the decisions made in a given year. Thus, for 1993-94, we received a total of 480 political science manuscripts. By August 15, decisions had been made on 391 of those, while 89 (including most of the 55 received in June) remained pending. The table reports acceptance rates by field among the 391 . The small numbers here inevitably mean more year-to-year fluctuation. In fields like international relations and formal theory, which receive about $10 \%$ of submitted manuscripts, an acceptance of four would yield a $10 \%$ acceptance rate; an acceptance of five would yield a $13 \%$ acceptance rate, while an acceptance of three would yield "only" a 7\% acceptance rate! Given these small numbers, the acceptance rates across fields are highly consistent. The over-all rate of $10 \%$ is similar to that under Patterson's editorship. Although we are receiving more manuscripts, we have had about the equivalent amount of additional space for publishing them.

\section{The Time to Process Manuscripts}

In previous Annual Reports I have described the process we use to select a panel of referees for 


\section{TABLE 2}

Distribution of Manuscripts Published by the APSR by Subfield in 1985-91 and 1992, 1993, 1994

\begin{tabular}{lcccc}
\hline \multicolumn{1}{c}{ Subfield } & $1985-91^{*}$ & 1992 & 1993 & 1994 \\
\hline American Politics and Public Policy & $42 \%$ & $34 \%$ & $39 \%$ & $36 \%$ \\
Comparative Politics & 16 & 17 & 19 & 23 \\
Normative Political Theory & 20 & 24 & 18 & 21 \\
International Relations & 10 & 13 & 14 & 9 \\
Formal Theory & 13 & 11 & 11 & 11 \\
Total & $101 \%$ & $99 \%$ & $101 \%$ & $100 \%$ \\
Number of Manuscripts & 49 & 53 & 57 & 53 \\
\hline
\end{tabular}

${ }^{*}$ Calculated from Patterson, Bruce and Crone, p. 766, Table 2; their figures are based on decisions made in the given academic year, not on date of receipt or publication; average total manuscripts excludes $1990-91$, for which only 31 new decisions were reported. each manuscript. The basic process was unchanged this year. The process led us to mail 1,576 manuscripts and requests for advice to 1,109 individuals. About 30 political science manuscripts were rejected without review, often for excessive length. These figures are roughly comparable to last year's.

Role of the Editorial Board. Again, the help of the Editorial Board members in advising on the selection of referees for almost all newly submitted manuscripts was of great value. Their dedication can be pointed up by reporting that $74 \%$ of their replies came within three days of our inquiry; another $12 \%$ came in the next two days (i.e., $86 \%$ of replies came within a week); $96 \%$ had arrived within 10 days. Many of these replies included not only evaluations of our suggested referees, but additional suggestions and, often, thoughtful analyses of appro- priately balanced panels. A few also raised points of potential concern about the approach described in the manuscript or warned us of conflicts of method or personality within a particular subfield. Such comments were extremely helpful to us in choosing referees for other manuscripts in the subfield, as well as in the specific case. To help avoid delays, advice was more frequently sought from multiple members of the Editorial Board than had been true in the past.

\section{Elapsed Time Statistics. Table 4} shows our report of the Elapsed Time in the review process. Having wrestled with these numbers for several years now, I must emphasize the difficulty created by the "moving target" nature of the subject. I cannot be sure about the comparability of figures across editors or journals, because a good
TABLE 3

Publication Acceptance Rates by the APSR by Subfield in 1985-1991 and in 1991-92, 1992-93, 1993-1994

\begin{tabular}{lcccr}
\hline \multicolumn{1}{c}{ Subfield } & $1985-91^{*}$ & $1991-92^{* *}$ & $1992-93^{* *}$ & $1993-94^{* *}$ \\
\hline American Politics and Public Policy & $11 \%$ & $15 \%$ & $13 \%$ & $11 \%$ \\
Comparative Politics & $11 \%$ & $11 \%$ & $10 \%$ & $12 \%$ \\
Normative Political Theory & $11 \%$ & $11 \%$ & $9 \%$ & $10 \%$ \\
International Relations & $11 \%$ & $18 \%$ & $18 \%$ & $7 \%$ \\
Formal Theory & $13 \%$ & $14 \%$ & $14 \%$ & $12 \%$ \\
Overall & $11 \%$ & $13 \%$ & $13 \%$ & $10 \%$ \\
Number of Decisions & na & 356 & 382 & 391 \\
\hline
\end{tabular}

${ }^{*}$ Calculated from Patterson, Bruce and Crone, p. 766, Table 3. Figures based on decisions in a given year, not on date of receipt or publication.

**Percentages are acceptances divided by acceptances plus rejections plus revise/resubmit, for manuscripts received from July 1 to June 30, decisions made as of mid August. Pending manuscripts are not included. (E.g. for 1993-94, 480 political science manuscripts had been received; decisions had been made on 391 , of which 41 were accepted, while 89 remained pending, as of August 15, 1994.) deal depends on just which statistic is reported for which period. The figures for referee replies and for final decision time are both highly dependent on the chosen time frame and statistic. If we use simple averages (means), the monthly times for response diminish steadily over the year. (This is because the figures for last fall can include outliers that are over six months old, while any early summer manuscripts that have completed the full review cycle are, by definition, going to have a short review time.) Including even a handful of June manuscripts in an August report will give a very optimistic picture for the year ending June 30 .

Medians are far more reliable for two reasons: (1) they are not affected by the extreme outliers of either the very slow reviews or those not reviewed at all; (2) as soon as half (plus one) of the manuscripts received in a month have been evaluated, we know what the median time for that month will be (it is the time of the last manuscript in, if exactly half plus one have arrived). Therefore, working on August 15, we can usually calculate accurately the median for each month for the first 11 months and have a number that would not change if we analyzed it again later.

Because of the greater reliability, in my view, of the median I have calculated Table 4 using the medians for all the months in which half (plus one) of the manuscripts had been returned. For 1993-94 this was the first 11 months. I have averaged those 11 monthly to get the yearly numbers. I have broken down Patterson's reported figures into the three years he reported medians and the three years he reported means. I have not been able to ascertain exactly which months within each year are included.

The data in Table 4 show that our performance falls well short of the remarkable record achieved by Patterson. I am quite confident that even the most comparable calculations would reveal the same fact. However, we continue to make gains, especially in handling the manuscripts in the initial review process. The median manuscript 
TABLE 4

Elapsed Time in the APSR Review Process (Work Days)

\begin{tabular}{|c|c|c|c|c|c|c|c|}
\hline $\begin{array}{c}\text { Processing } \\
\text { Stage }\end{array}$ & $\begin{array}{c}1981- \\
1982 \\
\end{array}$ & $\begin{array}{c}1982- \\
1983 \\
\end{array}$ & $\begin{array}{c}\text { Average } \\
\text { 1985-1988 } \\
\text { (med) }\end{array}$ & $\begin{array}{c}\text { Average } \\
1988-1991 \\
\end{array}$ & $\begin{array}{c}1991- \\
1992 \\
\end{array}$ & $\begin{array}{c}1992-1993 \\
\text { (med) }\end{array}$ & $\begin{array}{c}\begin{array}{c}1993-1994 \\
\text { (med) }\end{array} \\
\end{array}$ \\
\hline $\begin{array}{l}\text { rom receipt to } \\
\text { referee assignment }\end{array}$ & - & - & 7 & 11 & 26 & 22 & 16 \\
\hline $\begin{array}{l}\text { rom assignment to } \\
\text { last review }\end{array}$ & - & - & 45 & 40 & 44 & 41 & 41 \\
\hline $\begin{array}{l}\text { rom last } r \\
\text { to decisi }\end{array}$ & - & - & 4 & 7 & 9 & 5 & 5 \\
\hline $\begin{array}{l}\text { From receipt to } \\
\text { final decision }\end{array}$ & 71 & 64 & 55 & 52 & 72 & 65 & 63 \\
\hline \multicolumn{8}{|c|}{$\begin{array}{l}\text { Note: } 1981-82 \text { and } 1982-83 \text { are the first two years of the Zinnes editorship. Data from } \\
\text { Zinnes 1983, pp. } 811-812 \text {. Intermediate stages were not reported by Zinnes. 1985-1991 are } \\
\text { the Patterson editorship; data from Patterson, Bruce and Crone, Table 4, p. } 768 \text {. Data from } \\
\text { Zinnes and Powell are converted to working days (absolute calendar days are multiplied by } \\
5 / 7) \text {, for consistency with Patterson. 1992-93 and 1993-94 are based on the months for } \\
\text { which over half the manuscripts were completed and medians available at the time of } \\
\text { report ( } 9 \text { months in 1992-93 and } 11 \text { months in 1993-94.) }\end{array}$} \\
\hline
\end{tabular}

that is reviewed now spends about three weeks in our office before it is sent out for review. In that time the following steps have been completed:

(1) the manuscript has been logged into our records and assigned a number;

(2) it has been assigned to an $A P S R$ intern;

(3) the intern has read the manuscript;

(4) the intern has classified it as appropriate for review or turned it over to me for a decision to reject;

(5) the intern has prepared a description and a proposed list of available referees, checked these with me, and faxed them and the author's Abstract to at least one member of the Editorial Board;

(6) the intern has received the response(s) and recommended referees to me;

(7) I have chosen the referees;

(8) letters to the referees have been prepared and mailed.

Recall that two new manuscripts are arriving and entering this process each business day!

I am grateful to my $A P S R$ interns, to Associate Editor Linda Lindenfelser, and to the Editorial Board members for their efforts in reducing these processing times. For all or part of 1993-94 the interns were Frank Bell, Jay Goodliff, Nikolai Mikhailov, and Ethan
Zorick. I think that these times are approaching the best one can reasonably expect using this process. The process of consulting the Editorial Board is going to take about a week longer than working only in the local office and department. (By the way, the mean for this part of the process is also 16 working days, reflecting the relatively uniform handling of manuscripts.)

The median time in the total cycle-from receipt of the manuscript until mailing an editorial decisionfor the manuscripts received in the first 11 months of 1993-94 was 63 working days (88 total days), or about three months. While we are not proud of these numbers, which remain over a week and a half longer than the figures reported by Patterson for 1985-88, they seem to be acceptable by current standards in political science. As suggested above, I continue to believe that the benefit of the advice from the Editorial Board is, at least for me, worth an extra week of processing time.

Another View of Processing Time. Another way to look at processing time is to consider it from the point of view of the authors submitting manuscripts and the reviews they receive. One way we speed up the processing of manuscripts is to monitor the nature of the incoming referee reports. When two reports are received that recommend either outright rejection or the category
"Marginal importance/extensive revisions needed," I examine the reviews. If they are, indeed, negative, I reject the manuscript at that point. Although I read the reviews carefully, I do not ordinarily read these manuscripts myself. If a third review arrives later, it is sent to the author. This procedure was also used by previous editors and is, I would guess, fairly standard in political science. (I do not know whether most editors read these manuscripts.) In most cases, the "rejection with two" cases are handled promptly. Of course, no system is perfect and it is always possible that two consecutive readers had a day in which they were blind to the possibilities of a manuscript. But in the great majority of cases I think these decisions are accurate, and waiting for a third report would not change the decision.

In the first 11 months of 1993-94, we received 424 political science manuscripts. Of these, 387 were sent out for full review. Of those sent for full review, 152 were decided on the basis of two reviews, while 212 received three reviews and 23 remained pending on August 15. Assuming, fairly reasonably, that almost all those remaining pending will be decided on the basis of three reviews, we could say that the manuscripts sent out for review fell into two general categories, the $39 \%$ that were rejected on the basis of two reviews and the $61 \%$ that required a third review. The median processing time on the former was about 50 business days, a little over two months, compared to the 63 days (three months) for all manuscripts shown in Table 4.

To look at the manuscripts that take a long time for reviews, we can only consider the first part of the year. Examination of the manuscripts for the first seven months of the year, showed that of 268 manuscripts received in July-January, 23 either had taken over 180 days before a final decision was reached or were still pending and going to take that long. This is about $81 \frac{12}{2} \%$ of the manuscripts received in this period. Most of us in political science would consider this an excessively long time for a decision. I certainly 


\section{FIGURE 1}

Months Until Decision

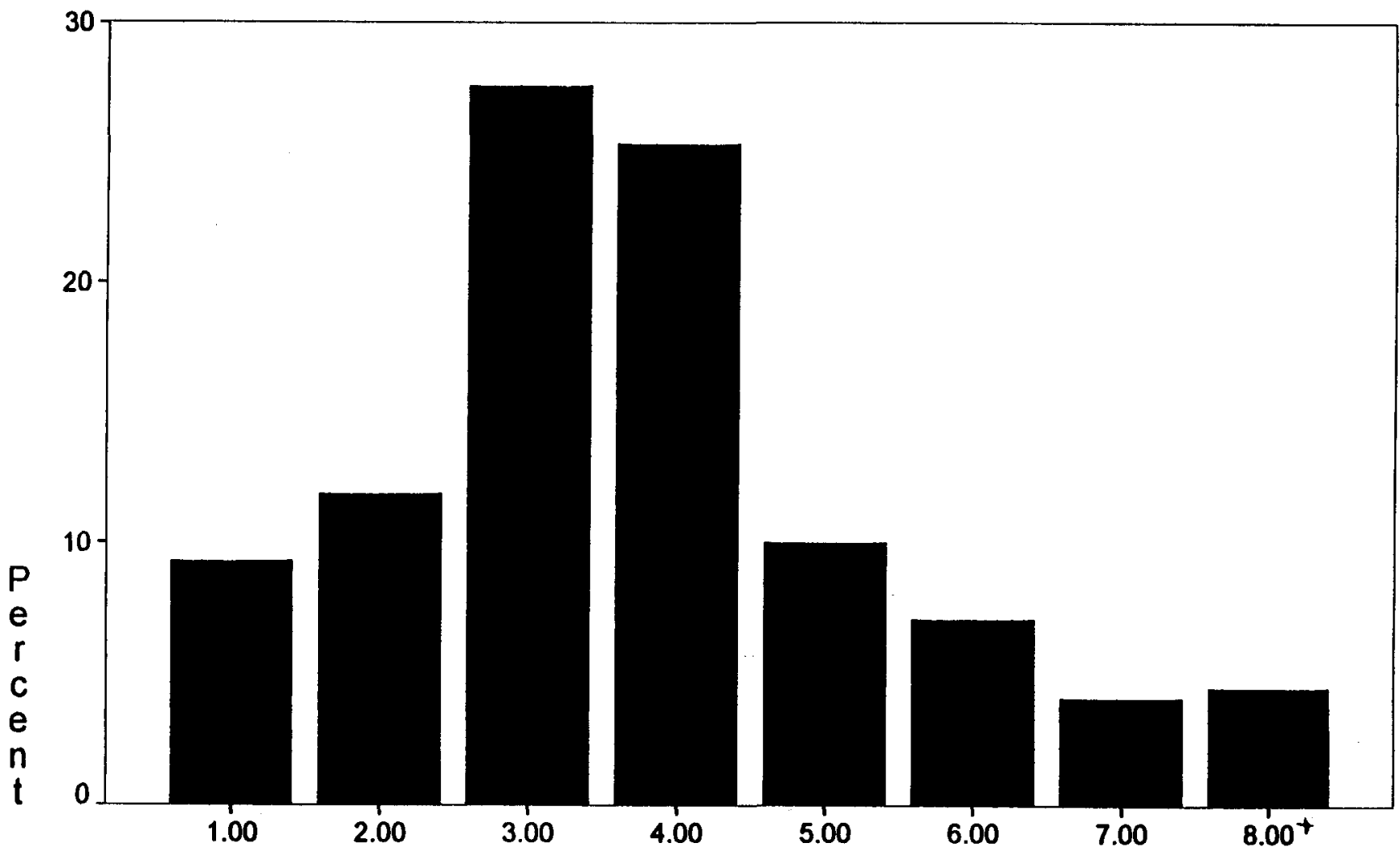

Months

share that view. The full distribution of times until a decision was made is shown in Figure 1.

I can summarize Figure 1 briefly in this way. A small number of manuscripts are rejected in a very short span of time, almost always within a month. This is the $9 \%$ bar at the far left of Figure 1. Authors of these manuscripts are, I think, receiving an appropriate processing response; although they are not necessarily happy with it, most accept it. Many of those rejected for length are resubmitted later.

Of the manuscripts sent out for review, over a third receive an expeditious, but negative, decision for which the median time is a bit over two months. These manuscripts make up the bulk of the cases in the next two bars of the graph.

The largest number of manuscripts, about half of them, receive decisions in a period between three and six months, based on three reviews. These decisions are a mix- ture of acceptances, rejections, "soft rejections," and encouraged "revise and resubmits." By far the largest numbers, of course, are rejected. For this group of authors we process the manuscripts reasonably efficiently, although it would be nice to do better. As shown in Figure 1, the bulk of the manuscripts receive decisions in the 61-90 or 91-120 day periods (these are calendar days), that is, in four months or less. Seventy-four percent of the manuscripts have been decided by the end of the fourth month. (Preliminary comparative analysis of our first two years suggests that last year only $66 \%$ of the manuscripts had been decided by the fourth month, and in 1991-92, only $57 \%$.) Some $10 \%$ of all manuscripts are decided in the fifth month; another $7 \%$, in the 6 th month.

A very small, but painful, subset of manuscripts, about $81 / 2 \%$ in the first seven months of 1993-94, wait over six months for a decision. As we see in the last two bars of Figure $1,4 \%$ are in the seventh month. The last bar reflects all additional months; there are a couple of manuscripts in most months up to a year. Of the 23 manuscripts in the over 6 months (180 calendar days) categories, three were accepted, two received encouraging revise/resubmits, fifteen were rejected, and three remain pending (despite our best efforts.)

These manuscripts are the most frustrating for both authors and editors. They seem to fall into two types. In one, the problem is drawn-out consecutive cancellations by referees. When the cancellations take a long time, (as when we do not discover the reader is out of the country until the absence of response to our cards and letters leads us to call after three months), a couple of sequential cancellations creates a refereeing disaster. In 1993-94, at least, manuscripts that 
entered the referee process in the early summer were particularly subject to this problem, ( 9 of the 23 manuscripts taking over 6 months for a decision were submitted in July), as are comparative politics manuscripts ( 8 of the 23 ). More unusually, an occasional manuscript just receives many cancellations. Although only about one referee in four cancels on average, we have had manuscripts that have taken 11 or 12 referees in order to get three evaluations.

The second problem occurs when we only gradually infer that a referee is not going to respond. By six months the lagging referees have all received reminder postcards, letters, and several telephone calls from the Associate Editor. Frequently, we add another referee. But we don't usually do this when we have spoken to the first referee and he/she promises us that a review will be forthcoming very soon. We tend to believe these promises, which are usually fulfilled. But when they are not, a referee can "string us along" for several additional months with repeated promises before we see the light and replace him or her. This is especially a problem when the referee has been highly recommended for the manuscript because of unusual substantive or methodological expertise that makes him/ her difficult to replace.

We continue to work to avoid the problems of excessive time to decision through monitoring, replacement of referees, and even initially sending to four referees when we have doubts about promptness. Preliminary analysis of our records for the first three years suggests that in $1991-92,111 / 2 \%$ of the manuscripts took longer than 6 months to decide; and that in 199293, the figure was $101 / 2 \%$, compared to the $81 / 2 \%$ in $1993-94$. But these difficulties are very hard to overcome. I do offer my most sincere apologies to those authors who have suffered from them.

\section{Book Review}

I am deeply grateful to Melissa Collie for her fine efforts over the past three years as Book Review Editor. It is a difficult and important job, which she has handled with great skill. Melissa is continuing to edit the Book Review Section through the March 1995 issue of the $A P S R$, which goes to press in late September. The incoming Book Review Editor, Mark Lichbach of the University of Colorado, has been receiving, evaluating, and assigning referees for all new books submitted for review since September 1 and will be editing all material to appear in the June 1995 issue. I look forward to working with him.

\section{References}

Patterson, Samuel C., John M. Bruce, and Martha Ellis Crone. 1991. "The Impact of the American Political Science Re- view." PS: Political Science \& Politics 24 (4):765-74.

Patterson, Samuel C., Brian D. Ripley, and Barbara Trish. 1988. "The American Political Science Review: A Retrospective of Last Year and the Last Eight Decades." PS: Political Science \& Politics 21 (4):908-25.

Patterson, Samuel C., and Shannon K. Smithey. 1990. "Monitoring Scholarly Journal Publication in Political Science: The Role of the APSR." PS: Political Science \& Politics 23 (4):647-56.

Zinnes, Dina A. 1983. "Report of the Managing Editor of the American Political Science Review.," PS 16 (Fall):810-13.

\section{Errata: 1994-96 APSA Directory of Members}

\author{
Alexander, Herbert E., Ph.D., \\ Yale University \\ Beck, Paul Allen, E-mail: \\ ts1449@ohstmvsa \\ Dunn, Charles DeWitt, Arkadel- \\ phia, AR 71923. Add to geo- \\ graphic index under Arkadelphia, \\ Arkansas. \\ Herrnson, Paul S., Associate Pro- \\ fessor, Phone: 301-405-4123, \\ Ph.D., University of Wisconsin- \\ Madison \\ Ravenhill, John, E-mail: \\ raven@coombs.anu.edu.au. \\ Russett, Bruce M., New Haven, \\ CT 06520-8301. Phone: 203-432- \\ 5233 \\ Sabato, Larry J., Delete from index \\ of minority members under the \\ heading of American Indian. \\ Watson, Cynthia, E-mail: \\ watsonc@ndu.edu
}

